\title{
Solute transport from geosphere to biosphere: Modeling results from the Forsmark site, Sweden
}

\author{
S. Berglund ${ }^{1}$, E. Bosson ${ }^{1}$, T. Lindborg ${ }^{1}$ and M. Sassner ${ }^{2}$ \\ ${ }^{1}$ Swedish Nuclear Fuel and Waste Management Co. (SKB), Box 250, SE-10124 Stockholm, \\ Sweden \\ ${ }^{2}$ DHI Sweden AB, Svartmangatan 18, SE-11129 Stockholm, Sweden
}

\begin{abstract}
This paper describes transport modeling performed by the Swedish Nuclear Fuel and Waste Management Company (SKB) within the recently completed SR-Site safety assessment. SR-Site is a part of the license application for building a deep geological repository for spent nuclear fuel in Sweden; this application was submitted to the authorities in March 2011. In the safety assessment, a suite of transport models was used to quantify radionuclide transport through the engineered and geological barriers and in the biosphere. The present paper is focused on the transport in the upper part of the bedrock and in the regolith (the Quaternary deposits overlying the rock). The results presented provide input to the assessment of uncertainties in calculated discharge locations for radionuclide-bearing groundwater from the considered repository volume and to analyses of solute spreading in near-surface and surface systems.
\end{abstract}

\section{INTRODUCTION}

The Swedish Nuclear Fuel and Waste Management Company (SKB) has performed an assessment of the long-term radiological safety of a deep geological repository at the Forsmark site, which was selected by SKB to host the planned final repository for spent nuclear fuel from the Swedish nuclear power plants. This safety assessment, which is called SR-Site, has recently been completed and published by SKB [1], and is included in the license application for building and operating the repository that was submitted to the authorities in March 2011.

In the SR-Site safety assessment, a suite of transport models was used to quantify radionuclide transport through the engineered and geological barriers and in the biosphere. Some of these models were integrated in the "model chain" used in the dose and risk calculations, whereas others were utilized in supporting modeling activities intended to test assumptions and simplifications made in the model development. In particular, radionuclide transport and dose modeling of the biosphere was used as a basis for quantifying the radiological consequences of hypothetical future releases from the repository [2]. However, these calculations were based on inputs from models describing the transport in the repository and geosphere parts of the system.

In the SR-Site biosphere modeling, SKB used a landscape model consisting of interconnected "biosphere objects" [3], e.g. lakes and associated catchment areas where radionuclide-contaminated groundwater could discharge in the event of a release from the repository. For these biosphere objects, radionuclide transport and doses were calculated using compartment models. The identification of discharge areas and biosphere objects, and the description of the processes governing solute transport to and within them (including model resolution) are examples of important aspects of the biosphere analyses that were investigated in supporting modeling activities.

This paper describes some of the transport modeling that was carried out in order to support the biosphere analyses in SR-Site. Specifically, it presents modeling of solute transport in the near-surface system composed of the upper part of the bedrock and the overlying regolith, which at Forsmark consists of Quaternary deposits. The modeling discussed in this paper consists of particle tracking and 


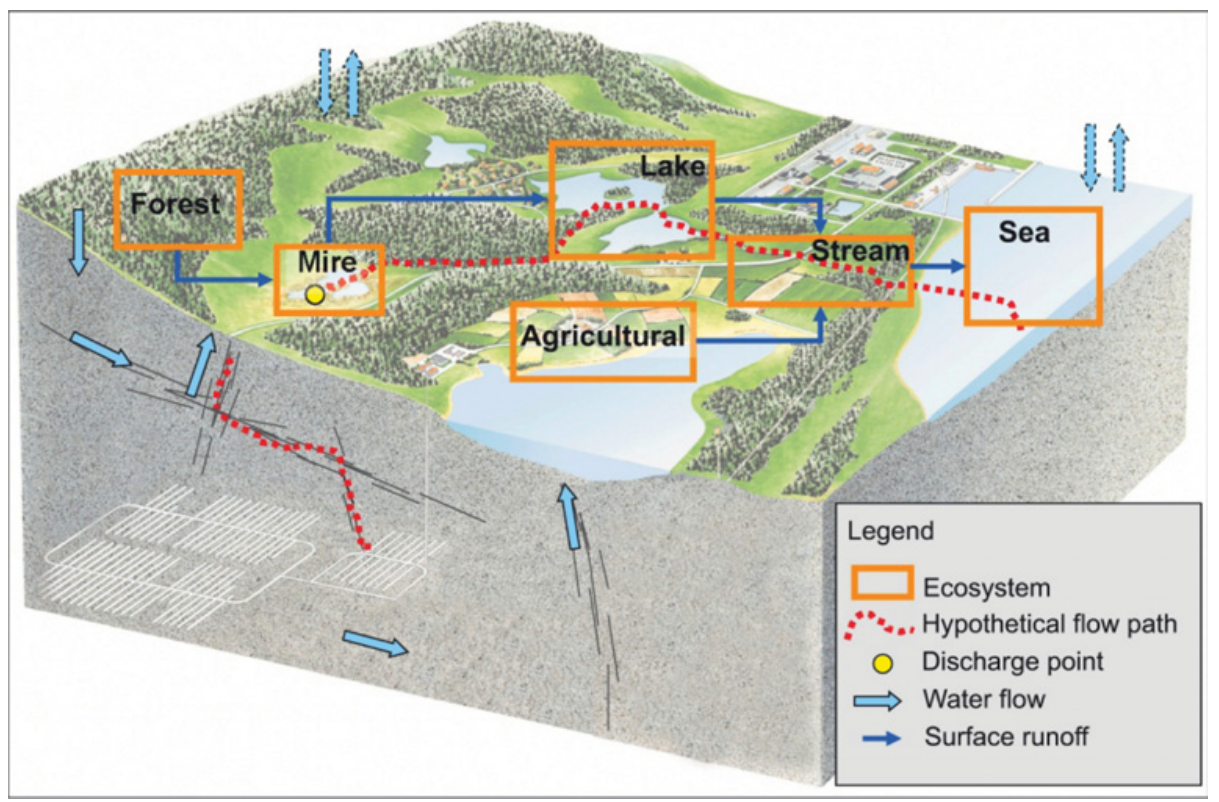

Figure 1. Conceptual model of solute transport along a hypothetical flow path (dotted line) from the spent fuel repository (indicated by the white lines in the grey bedrock part of the model) up to a discharge point (the larger dot in the "Mire" box), and further through different types of ecosystems to the sea (figure from [3]).

advection-dispersion simulations performed with the MIKE SHE tool [4]. The main objectives of this modeling was to investigate uncertainties related to predicted discharge locations of potentially radionuclide-bearing groundwater from the planned repository volume and to study solute spreading in the near-surface and surface systems.

\section{DATA AND MODELS}

\subsection{Conceptual and numerical models}

Figure 1 shows a generic conceptual model of radionuclide transport from the planned repository at a depth of c. 500 meters in the bedrock up to the surface, and further within and between different types of surface ecosystems. A hypothetical flow path, along which dissolved radionuclides could be transported, is shown as a dotted line in the figure. Note that the figure emphasizes the mainly horizontal transport near and on the surface, whereas the mainly vertical transport through fractures and deformation zones in the bedrock is greatly simplified. This conceptual model provides a common basis for the development of site-specific ecosystem and landscape models, which, in turn, constitute an important input when developing the models used in biosphere transport and dose calculations.

Site-specific geological and hydrogeological data and models are instrumental when developing conceptual and numerical transport models for a particular site. Figure 1 indicates that the transport problem at hand involves different types of systems or domains (e.g. bedrock, regolith and surface water systems), which require different types of models. In the SR-Site modeling of groundwater flow and transport by groundwater, integrated and relatively large-scale hydrogeological models, which consider the whole bedrock-regolith system including the repository, were used to calculate flow paths from the repository to the surface [5]. The discharge locations obtained from these flow paths were then used as a basis for the development of landscape models [3] and biosphere transport and dose models [2, 6]. 
The integrated hydrogeological models used to calculate discharge locations involve large model volumes and are by necessity simplified in terms of the representation of, for example, the details of the uppermost part of the system. Therefore, more detailed hydrological models focusing on the processes in the upper bedrock and the regolith and the interactions between soil, vegetation and atmosphere were also developed [4]. The main purpose of these models was to provide input to the biosphere transport and dose modeling (e.g. water fluxes between different model compartments), but they were also used to test the discharge locations predicted by the large-scale models.

In addition, the detailed near-surface/surface system models were used to investigate the relevance of simplifications made in the biosphere transport and dose models, and as an input to the supporting transport modeling discussed in this paper. The main aim of this modeling, which is described in more detail by Lindborg [3], was to improve the understanding of solute transport in the regolith, i.e. the time scales and spatial distributions of solutes entering the regolith by groundwater flow from the bedrock. Retention of radionuclides due to, for example, sorption has also been considered in the SR-Site modeling [2, 7], but is not discussed here.

\subsection{Site overview}

SKB has performed site investigations for a final repository for spent nuclear fuel at two different locations in Sweden, referred to as the Forsmark and Laxemar-Simpevarp areas. In June 2009, the Forsmark site was selected by SKB as the site for the repository. Forsmark is located in central Sweden within the municipality of Östhammar, about $120 \mathrm{~km}$ north of Stockholm. The area is situated along the shoreline of Öregrundsgrepen, a funnel-shaped bay of the Baltic Sea, and is characterized by a smallscale topography at low altitude. The whole area is located below the highest coastline associated with the last glaciation, and large parts of the candidate area emerged from the Baltic Sea only during the last 2,000 years. Both the flat topography and the still ongoing shore-level regression of c. $6 \mathrm{~mm}$ per year strongly influence the current landscape [8].

The area constitutes a typical coastal area at the shoreline of the Baltic Sea in northern Uppland. Post-glacial land uplift, in combination with a flat topography, implies fast shoreline displacement that has resulted in a very young terrestrial system that contains a number of newborn shallow lakes and wetlands. Sea bottoms are continuously transformed into new terrestrial areas or freshwater lakes, and lakes and wetlands are successively covered by peat. The lakes themselves are also of a specific type that is only found in northern Uppland. Shallow and with sediments rich in calcium, the lakes are unique in Sweden. Till is the dominant Quaternary deposit, and hence the main component of the regolith, whereas granite is the dominant rock type. The annual precipitation and runoff are c. 560 and $150 \mathrm{~mm}$, respectively.

In the radionuclide transport and dose modeling of Forsmark, areas with lakes or streams surrounded by wetlands are of particular interest when defining and describing transport conditions in the biosphere objects that constitute the main components of the landscape model [3]. The landscape model consists of a set of interconnected biosphere objects. Due to shoreline displacement and other processes contributing to formation, infilling and terrestrialization of lakes and wetlands, these objects are subject to a succession, which in many cases includes submerged (by the sea), lake, wetland and terrestrial stages. In particular, lakes will gradually decrease in size and become wetlands, and then possibly further develop into land areas that in some cases may be suitable for agriculture. This succession is an important component of the landscape and radionuclide transport models developed within SR-Site $[2,3,6]$.

\subsection{Transport models used in the present work}

This paper is focused on the MIKE SHE transport modeling performed in support of the biosphere assessment, and presents example results of relevance for the understanding of near-surface transport 
conditions in typical discharge areas in Forsmark. A detailed description of the modeling is provided by Bosson et al. [4]. Flow and transport modeling with MIKE SHE of present and future conditions at Forsmark has been performed using different model scales and resolutions; the present paper considers results from the models termed "local models", which have a horizontal grid resolution of $20 \mathrm{~m}$ by $20 \mathrm{~m}$.

The transport analyses include particle tracking, in which flow paths are traced by imaginary particles that follow the flowing groundwater, and advection-dispersion simulations, in which a solute is transported both by the modeled groundwater flow field and by dispersion, which essentially is a lumped representation of small-scale velocity variations and diffusion. No processes other than advection and dispersion are taken into account in the present MIKE SHE modeling.

The solute transport simulations have been performed using different types and locations of sources. In particular, the focus is here on simulations where the particle starting positions and the sources in the advection-dispersion models have been placed at c. $-40 \mathrm{~m}$ (elevation relative to the present sea level) along flow paths obtained from the integrated bedrock hydrogeology modeling. This means that sources are placed along the flow paths identified and used in the safety assessment calculations, and that the emphasis here is on the transport in the uppermost part of the rock and the regolith. All local model calculations are based on the modeled 10,000 AD shoreline position and distribution of Quaternary deposits. This means that processes leading to terrestrialization of present and future lakes are taken into account. At 10,000 AD all lakes within the considered local model areas have turned into land areas and the surface water system consists of a stream network only.

\section{RESULTS}

\subsection{Particle tracking results}

Since the starting positions of the particles in the MIKE SHE particle tracking simulations were located along the flow paths calculated by the integrated bedrock hydrogeology model, comparison of the discharge locations in the two models could be used to assess the effects of a more detailed representation of the near-surface domain and the processes there. Specifically, such comparisons show whether the same biosphere objects would be identified, and also if there are differences in the detailed discharge locations within the objects.

The results of the modeling performed in connection with SR-Site [4] show that the differences between the results from the two models are very small for the particles going to surface streams. However, some differences can be observed in the former lake areas. The particles leaving the MIKE SHE model tend to be more concentrated along the shorelines of the terrestrialized lakes, whereas the particles from the integrated bedrock model appear in the central parts of the lakes. This indicates that the boundaries between the lake areas and their surroundings have some relevance for groundwater discharge even when the lakes have developed into wetlands and land areas. Irrespective of these observations, the general impression is that the differences in the overall discharge pattern are small.

\subsection{Advection-dispersion results}

As part of the MIKE SHE supporting transport analyses, flow paths from ten canister positions in the repository with relatively high groundwater flow rates in the deposition holes and relatively short travel times to the ground surface were selected and used to obtain source locations for the advectiondispersion modeling. Separate simulations were performed for each source/flow path; in the grid cell at an elevation of approximately $-40 \mathrm{~m}$ along the flow path, a continuous and constant concentration source of $1 \mathrm{~g} / \mathrm{m}^{3}$ was set in MIKE SHE.

Figure 2 shows an example of results from one of the simulations; the left part of the figure shows the surface distribution in the uppermost layer of the model, and the right part concentration profiles at different times during the simulation. The strength of the constant source is $1 \mathrm{~g} / \mathrm{m}^{3}$ but the concentration in the surface layer is very low, except directly above the solute source. The figure shows that the solute 


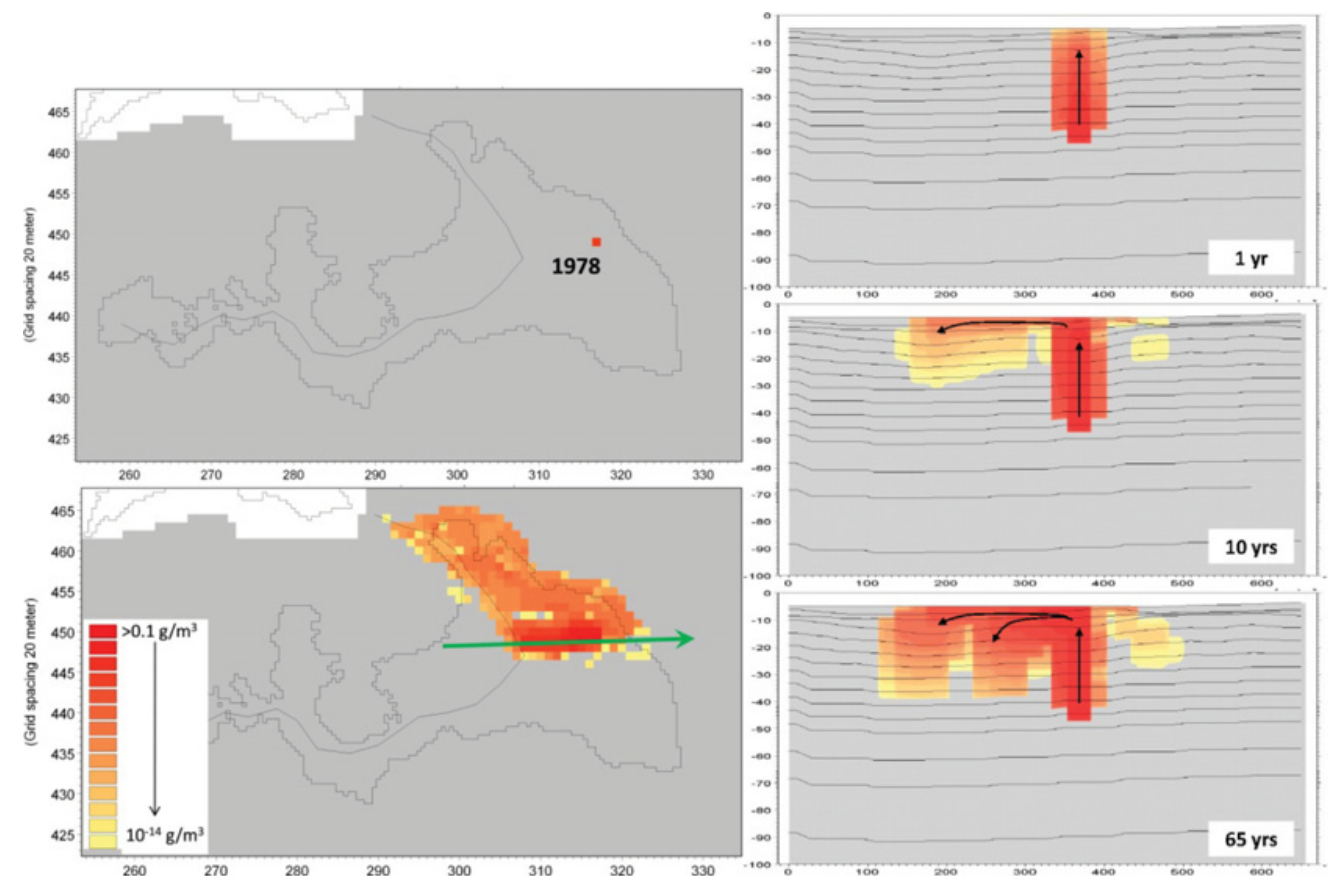

Figure 2. Left: Surface plots of a terrestrialized lake (former lake contour shown); dark colors correspond to high concentrations [4]. The upper figure shows the location of the source (which is at $-40 \mathrm{~m}$ ), and the lower figure the solute plume in the uppermost layer after 65 years. Note that the length scale is in number of grid cells and should be multiplied by 20 for conversion to meters. Right: Concentrations after 1,10 and 65 years of simulation along the profile indicated by the green arrow in the lower left figure [4].

is mainly transported directly to the stream (indicated by the line going through the lake area). However, part of the solute mass is spread horizontally over a larger area. The concentration profiles show that the solute is mainly transported vertically upwards to the surface and when it has reached the surface it starts spreading in the horizontal direction in the top layer. The solute spreads both horizontally and vertically from the part of the top layer where it first arrives from below.

The large concentration interval considered in Figure 2, i.e. from a lowest displayed concentration of $10^{-14} \mathrm{~g} / \mathrm{m}^{3}$ to the source concentration $1 \mathrm{~g} / \mathrm{m}^{3}$, is useful to indicate transport directions, but probably exaggerates the area that realistically can be considered affected by transport from the source substantially. To investigate the sensitivity to the selected minimum concentration and perhaps obtain more relevant quantifications of contaminated areas, also a smaller concentration interval with the lowest value at $10^{-5} \mathrm{~g} / \mathrm{m}^{3}$ was studied (results not shown). The contaminated area is much smaller in this case (c. $50 \mathrm{~m}$ by $200 \mathrm{~m}$, compared to c. $200 \mathrm{~m}$ by $500 \mathrm{~m}$ in Figure 2), but still much larger than the source size $(20 \mathrm{~m}$ by $20 \mathrm{~m})$.

The results presented above emphasize the importance of the remaining surface water, i.e. the stream network, for near-surface solute transport in discharge areas. Results similar to those in Figure 2 were obtained also for several other flow paths. However, in some simulations somewhat different patterns of solute spreading were observed, i.e. both examples of much less spreading in the regolith and cases with more extensive spreading in the bedrock than that observed in Figure 2 [3, 4].

\section{DISCUSSION AND CONCLUSIONS}

The results of the MIKE SHE local model transport simulations with particle releases or concentration sources in the upper part of the bedrock (along modeled flow paths from canister positions in the 
repository) show that solute transport in most cases is directed more or less vertically up to the regolith, where horizontal spreading might take place. Modeled discharge locations are concentrated to the surface streams and the former lakes in the model area (at the time considered, all lakes in the model area have turned into land areas). In particular, the particle tracking yielded discharge points along the former lake shorelines. The main reason for this is probably that the relatively low hydraulic conductivities of the lake sediments make the particles move towards the shorelines instead of through the sediments. Another possible reason for the horizontal transport towards the lake shorelines is the water uptake in the vegetation surrounding the lakes; the water uptake generates groundwater flow from below the lakes towards surrounding land areas.

The results of the advection-dispersion simulations show that solute spreading in some cases leads to relatively large areas with solute present in the surface layer, even if the source areas are small and relatively close to the surface. In some of the simulations, extensive spreading takes place already in the bedrock, whereas others show large differences between contaminated areas in the upper rock and the regolith. In particular, solute transport in the bedrock is diverted in the areas where horizontal fractures exist in the near-surface rock. Hence, a possible interpretation is that a typical pattern of near-surface solute spreading cannot be identified. However, it is noted that solute transport generally is directed towards the remaining parts of the surface water system, i.e. the stream network on the surface. This shows that the large scale topography governs the locations of discharge areas of deep groundwater.

The comparison between discharge points obtained from the integrated bedrock hydrogeology modeling and the MIKE SHE near-surface modeling shows that the results are similar in terms of the overall discharge pattern and regarding objects receiving particles, whereas there are some differences in the detailed discharge locations. In the areas of the former lakes, the discharge points in the MIKE SHE model tend to be more concentrated along the shorelines of the lakes, whereas the particles in the bedrock model to larger extent appear in the central parts of the lakes. For the particles going directly to surface streams, the differences between the results from the two models are very small. These results indicate that the overall discharge pattern, and hence the identification of biosphere objects, is not very sensitive to whether a detailed representation of the surface system is included in the model used to calculate discharge locations.

It can be concluded that there is some variety in the near-surface transport conditions in different parts of the area. However, the results also show common features, especially for the new land areas formed due to shoreline displacement, such that the initial transport from the sources is mainly vertical and that high concentrations are found within relatively small areas and usually directly above the sources. Finally, it is noted that the identification of a contaminated area based on advection-dispersion modeling is a matter of definition, since different concentration intervals (i.e. different cut-offs in the concentration intervals plotted) give different impressions of the degree of spreading and the size of the area affected.

\section{References}

[1] SKB, Long-term safety for the final repository for spent nuclear fuel at Forsmark, Main report of the SR-Site project, SKB TR-11-01 (Svensk Kärnbränslehantering AB, Stockholm, Sweden, 2011).

[2] Avila R., Ekström P.-A., Åstrand P.-G., Landscape dose conversion factors used in the safety assessment SR-Site, SKB TR-10-06 (Svensk Kärnbränslehantering AB, Stockholm, Sweden, 2010).

[3] Lindborg T., Landscape Forsmark - data, methodology and results for SR-Site, SKB TR-10-05 (Svensk Kärnbränslehantering AB, Stockholm, Sweden, 2010).

[4] Bosson E., Sassner M., Sabel U., Gustafsson L.-G., Modelling of present and future hydrology and solute transport at Forsmark, SR-Site Biosphere, SKB R-10-02 (Svensk Kärnbränslehantering AB, Stockholm, Sweden, 2010). 
[5] Selroos J.-O., Follin S., SR-Site groundwater flow modelling methodology, setup and results, SKB R-09-22 (Svensk Kärnbränslehantering AB, Stockholm, Sweden, 2010).

[6] SKB, Biosphere analyses for the safety assessment SR-Site - synthesis and summary of results, SKB TR-10-09 (Svensk Kärnbränslehantering AB, Stockholm, Sweden, 2010).

[7] Piqué A., Grandia F., Sena C., Arcos D., Molinero J., Duro L., Bruno J., Conceptual and numerical modelling of radionuclide transport in near-surface systems at Forsmark, SR-Site Biosphere, SKB R-10-30 (Svensk Kärnbränslehantering AB, Stockholm, Sweden, 2010).

[8] SKB, Site description of Forsmark at completion of the site investigation phase, SDM-Site Forsmark, SKB TR-08-05 (Svensk Kärnbränslehantering AB, Stockholm, Sweden, 2008). 